\title{
Potensi Objek Watu Kapal Sebagai Destinasi Geowisata Di Desa Srimulyo, Kecamatan Piyungan, Kabupaten Bantul
}

\author{
Fandika Agustiyar ${ }^{l}$, Hendry Wirandok ${ }^{2}$, Rois Naimudin ${ }^{3}$ \\ ${ }^{1,2,3}$ Fakultas Teknologi Mineral, UPN Veteran Yogyakarta \\ ${ }^{1} 114190085 @$ student.upnyk.ac.id
}

\begin{abstract}
Sitimulyo village has been known by the public with the tourist destination Watu Kapal. Watu Kapal object has an extraordinary attraction and potential to be developed into geotourism judging by the characteristics of geology, socio-cultural, educational values, conservation and creative economy of the community. This research aims to find out the potential of "Watu Kapal" as the development of geotourism objects. Methods used in the form of field surveys, qualitative and quantitative descriptions of research sites. The assessment was conducted with reference to Kubalikova (2013). The results of the study obtained a value of 63.5\%, indicating that the object Watu Kapal has the potential to be developed into a geotourism object. In the development of geotourism objects to be more optimal, further research and infrastructure development is needed.
\end{abstract}

Keywords: Conservation, Education, Geology, Geotourism, Tourism

Article Information:Submission: 30 July 2021, Published: 10 Agustus 2021

DOI: -

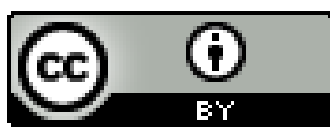

Copyright $(02021$ by the author(s). This article is published by Sekolah Tinggi Pariwisata Sahid Surakarta, Indonesia under the Creative Commons Attribution (CC BY 4.0) license. Anyone may reproduce, distribute, translate, and create derivative works of this article (for both commercial and noncommercial purposes), subject to full attribution to the original publication and author(s). The full terms of this license may be seen at https://creativecommons. org/licenses/by/4.0/

\section{PENDAHULUAN}

Dilihat dari geologi regional, pulau Jawa adalah bagian dari busur gunungapi dengan umur sekitar tersier hingga kuarter (Busur Sunda). Adanya tabrakan antara lempeng Samudera Hindia dengan lempeng Benua Eurasia berakibat terhadap terjadinya penunjaman di bagian selatan
Pulau Jawa. Menurut Bachri (2014) hal tersebut berakibat pada terjadinya superimposed volcanism atau kondisi terjadinya tumpang tindihnya gunungapi. Kompleksnya proses geologi yang terjadi, menghasilkan keanekaragaman bentuk muka bumi yang unik di wilayah Pulau Jawa. 
Bantul sebagai salah satu kab upaten dari Provinsi Daerah Istimewa Yogyakarta menjadi bagian wilayah pulau Jawa dengan beragamnya geodiversity (Ali et al., 2021). Kondisi lokasi yang secara morfostruktur berupa graben dengan tutupan deposisi material piroklastik, hal tersebut terjadi berhubungan dengan aktivitas erupsi Gunung Merapi (Santosa \& Adji, 2014). Keanekaragaman dan kekayan asset geologi tersebut sangat potensial untuk dikembangkan menjadi kawasan geowisata yang berkelanjutan.

Pemanfaatan asset geologi melalui sektor pariwisata akan memiliki manfaat yang luar biasa. Geowisata tidak hanya sebatas menawarkan unsur keindahan suatu objek saja, melainkan didalamnya terdapat banyak hal yang dapat diperoleh seperti nilai budaya dan historis yang dapat disajikan melalui story telling yang kreatif dan inovatif menyangkut geosite tersebut, sehingga meningkatkan daya tarik lebih terhadap masyarakat. Pengembangan kawasan geowisata juga mendorong peningkatan upya konservasi situs geologi dan keragaman hayati. Saat ini geowisata mulai banyak diminati oleh khalayak umum karena menyajikan suatu paket wisata yang lengkap, khas, langka, edukasi, indah dan menarik. Oleh sebab itu, pemenuhan dan pengoptimalan suatu geosite untuk geowisata semakin ditingkatkan.

Analisis kajian ini bertujuan untuk melakukan penilaian terhadap kelayakan geosite watu Kapal di Desa Srimulyo untuk dikembangkan menjadi kawasan geowisata dengan memperhatikan parameter - parameter seperti nilai Pendidikan, ekonomi, pendekatan ilmiah, konservasi dan nilai tambah.

\section{TINJAUN PUSTAKA \\ Pariwisata}

Ditinjau dari etimologis, istilah pariwisata merupakan gabungan kata dari bahasa Sansekerta "Pari" memiliki arti berkeliling atau Bersama dan kata "wisata" yang berarti perjalanan (Silviany, 2016). Berarti pariwisata merukapan suatu kegiatan perjalanan berkeliling dari suatu tempat menuju ke tempat lain (Utomo et al., 2017). Berdasarkan UU RI No 10 tahun 2009 pada pasal 1 ayat 3 dinyatakan bahwa Pariwisata adalah berbagai macam kegiatan wisata dan didukung berbagai fasilitas serta layanan yang disediakan oleh masyarakat, pengusaha, Pemerintah, dan
Pemerintah Daerah. Sedangkan pengertian Pariwisata menurut beberapa ahli diantaranya:

1. A.J Burkart dan S.Medklik

Dalam karyanya Tourism: Past Present and Future (Burkart \& Medklik, 1988), pariwisata adalah perpindahan orang dalam sementara waktu dan dalam jangka waktu yang sebentar ke tujuan tempat diluar dari mereka hidup, bekerja dan mereka melakukan aktivitas di tempat tujuan itu.

2. Richard Sihite

Pariwisata merupakan perjalanan sementara waktu yang dilakukan oleh sesorang, dilakukan dari suatu tempat ke tempat yang lain dengan meninggalkan tempat semula, dengan rencana dan maksud tidak untuk mencari nafkah pada tempat yang akan deikunjungi, melainkan untuk menikmati berkegiatan rekreasi dan bertamasya atau dalam rangka memnihi keinginan yang beraneka ragam (Putri, 2013; Richard Sihite, 2000).

3. James J.Spillane

Pariwisata adalah suatu kegiatan perjalanan yang tujuannya untuk memperoleh kenikmatan, kepuasan, mengetahui sesuatu, meningkatkan kualitas kesehatan, menikmati olahraga atau istirahat, menjalankan tugas, berziarah dan lainlain (James J, 1987)

Pariwisata menjadi sektor paling besar dan terkuat mengenai perekonomian dunia (Soebagyo, 2012). Sektor ini menjadi pendorong utama dalam peningkatan ekonomi dunia karena potensi keuntungan yang dapat menghasilkan devisa yang besar bagi negara, membuka lapangan kerja dan sebagai perangkat untuk memperkenalkan budaya (Sabon et al., 2018). Berdasarkan data dari United Nations World Tourism Organizaton (UNWTO), pariwisata memiliki peranan penting dan 
berkontribusi sebanyak $9 \%$ dari total keseluruhan GDP dunia (UNWTO, 2014).

\section{Geowisata}

Geowisata merupakan bagian bentuk dari kawasan wisata alam yang berfokus pada objek geologi dan landscape, untuk mempromosikan geo site dan keanekaragaman objek geologi serta pemahaman terkait kebumian melalui apresiasi dan kegiatan pembelajaran melalui kunjungan independent terhadap fenomena geologi, melhat pemandangan, menelusuri geo trails, tur berpemandu, geo activities dan patronase dari pusat wisatwan situs objek geologi (Dowling \& Newsome, 2010). Geowisata mampu mendorong dalam aktivitas konservasi geodiversity, biodiversity dan cultural diversity (Cahyani et al., 2020). Dalam pengembangan wisata suatu daerah geowisata menjadi aspek yang penting, hal itu disebabkan daya tarik pada objek wisata alam dikontrol oleh kondisi tatanan geologi daerah tersebut (Septian et al., 2019).

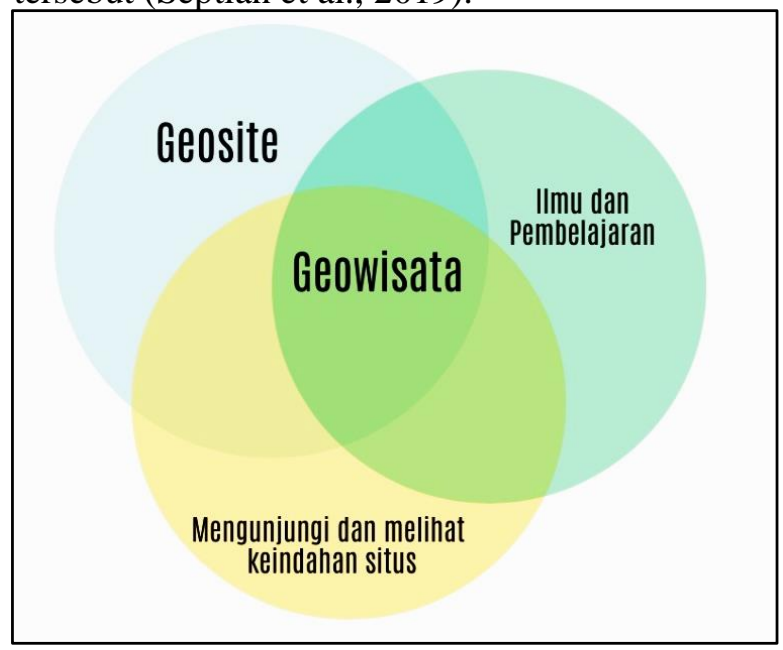

Gambar 1. Konseptual Geowisata

Dalam pengembangan objek geowisata terdapat beberapa istilah yang berkaitan, seperti "Geologi"-kajian studi ilmu kebumian: "Geoheritage"-warisan situs geologi; "Geoconservation"-pelestarian fitur bumi; "Geosite-situs untuk pengembangan ilmu kebumian atau sebagai destinasi wisata; "Geopark" -wilayah geologi terpadu untuk konservasi, pengembangan edukasi, dan sustainable development.

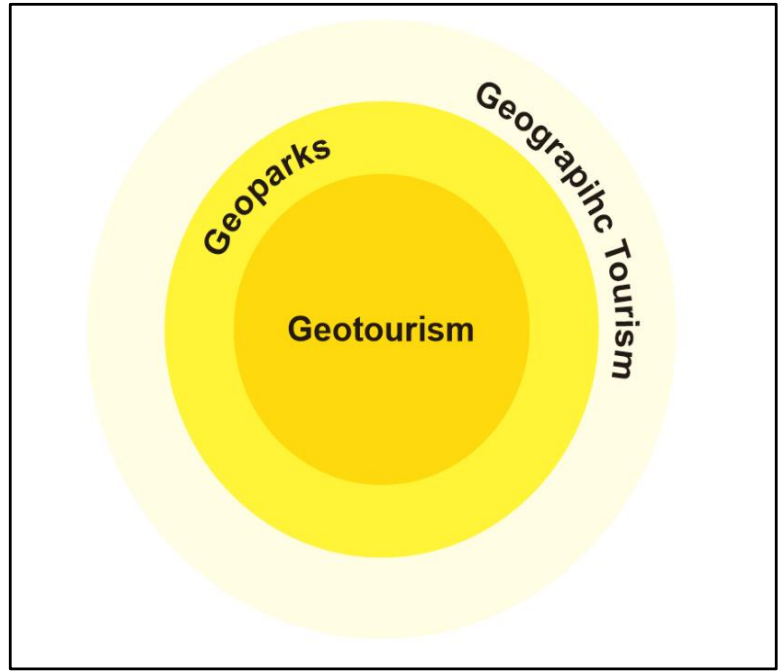

Gambar 2. Spektrum Geowisata

Desain ulang oleh penulis, konsep mengacu

(Sumber: Newsome, 2006)

Geowisata menjadi aktivitas utama dari geopark yang menjadi bagian dari wisata geografis. Pengembangan ekonomi akan terjadi dari aktivitas berwisata di objek geowisata. Geopark juga memiliki faktor yang penting terhadap pengembangan geowisata, pengelolaan geopark yang optimal akan mampu meningkatkan ekonomi lokal bagi masyarakat. Dalam aktivitas geowisata banyak melibatkan banyak aspek seperti akasesbilitas, transportasi, akomodasi, perencanaan, pelayanan, manajemen dan stakeholder (universitas, investor, pemerintah, perencanaan dan organisasi) (Permadi et al., 2019)

\section{METODE}

Penelitian ini dilakukan dengan metode survei dan observasi pada daerah penelitian yang secara geografis terletak di Dusun klenggotan, Srimulyo, Piyungan, Bantul pada koordinat $439727.26 \mathrm{~m}$ E dan $9135432.88 \mathrm{~m} \mathrm{~S}$. 


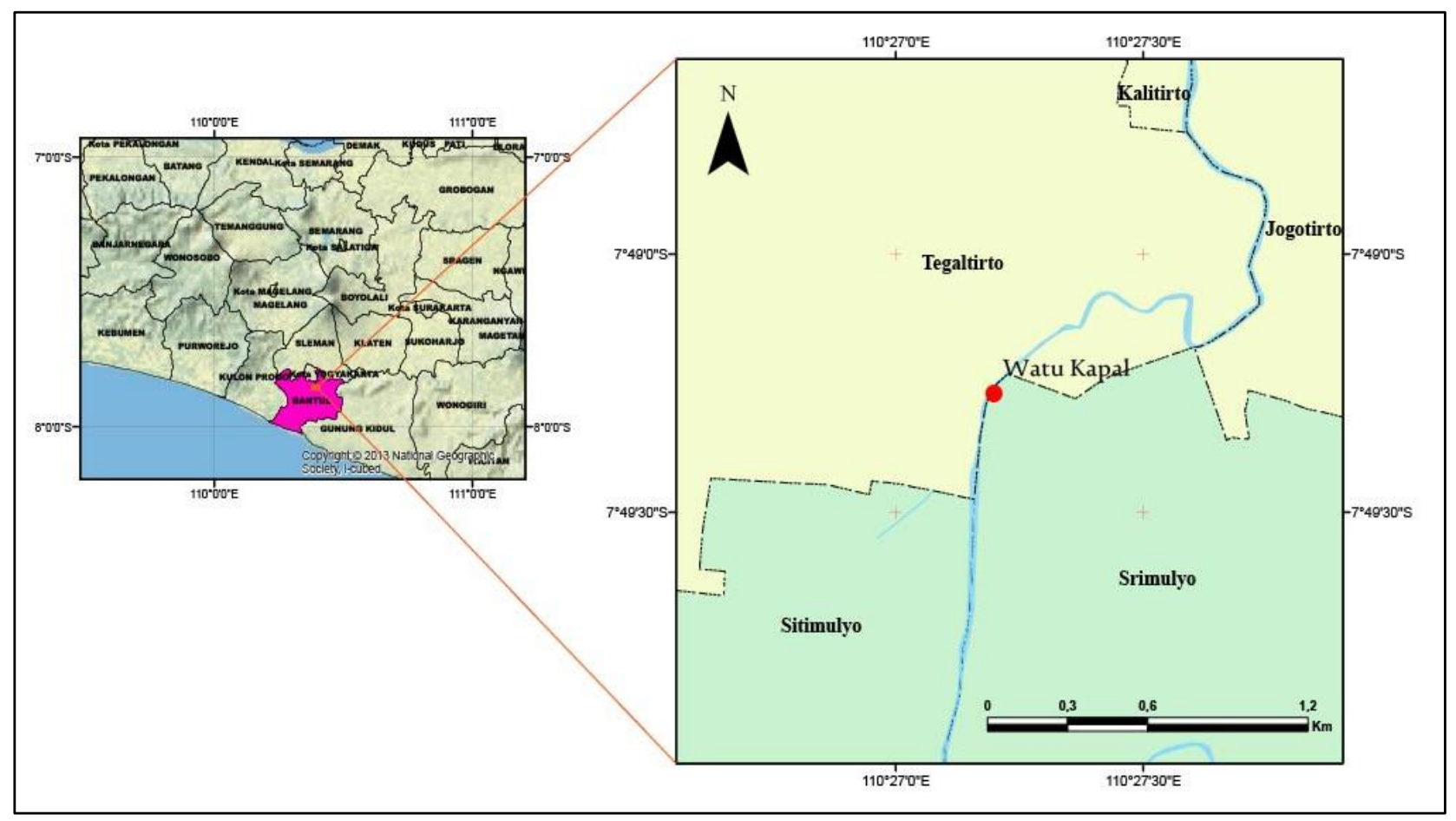

Gambar 1. Peta Geosite Watu Kapal

Pendekatan kualitatif dan kuantitatif dilakukan pada penelitian ini. Metode kualitatif dilakukan secara deskriptif melalui survei, observasi dan pengambilan data di lapangan meliputi data prodil daerah penelitian, koordinat lokasi, litologi geosite, struktur geosite, geomorfologi, kondisi geosite, persebaran geosite, kondisi saran dan prasarana sekitar geosite, aksesbilitas menuju lokasi dan kondisi permasalahan di sekitar geosite. Metode ini bertujuan untuk mengeksplorasi kondisi atau keadaan dari objek yang dikaji dengan memperhatikan aspek sosial dan lingkungan daerah penelitian.

Metode kuantitatif dilakukan dengan melakukan skoring dan klasifikasi terhadap kesiapan dan kelayakan (site evaluation) terhadap potensi geosite untuk dikembangkan menjadi geowisata. Dalam melakukan penilaian kelayakan geosite parameter yang digunakan meliputi nilai keilmuan dan intrisik, Pendidikan, konservasi, ekonomi dan nilai tambahan. Kelayakan geosite untuk diprioritaskan dikembangkan menjadi geowisata dilakukan dengan melakukan penilai akhir berupa menghitung rata- rata dari nilai keseluruhan yang diperoleh, kemudian melihat nilai akhirnya untuk nantinya diketahui geosite tersebut layak atau tidak untuk dijadikan kawasan geowisata. Dalam penilaian akhir apabila skor yang didapatkan $<50 \%$, maka geosite tersbut belum layak untuk dijadikan kawasan geowisata, sehingga perlu pembenahan dari poin - poin yang masih dinilai kurang dan rencana pengembangan yang lebih optimal, sedangkan jika nilai rata-rata $>50 \%$ maka area geosite tersebut layak untuk dikembangkan menjadi kawqasan geowisata. Untuk mengkaji dalam terkait penilaian potensi geosite untuk geowisata selanjutnya dilakukan korelasi data antara hasil analisis kualitantif dengan kondisi daerah penelitian.

\section{HASIL DAN PEMBAHASAN Karakter Geologi}

Berdasarkan hasil pengamatan lapangan di lokasi wisata watu kapal Desa Srimulyo dijumpai beberapa litologi dan struktur geologi yang berkembang. Secara litologi daerah ini terdiri atas batuan piroklastik berbutir halus berupa tuff dengan warna abu-abu, dengan struktur masif. Jika dilihat dari stratigrafi pegunungan selatan, maka litologi daerah ini termasuk dalam formasi semilir yang tersusun atas batuan piroklastik (Surono, 2009). Struktur geologi yang terdapat pada lokasi penelitian berupa sesar dan kekar, serta lipatan yang belum diidentifikasi lebih lanjut. Sesar yang berkembang berupa sesar turun 
yang berarah relatif utara-selatan dengan kedudukan sesar N 1800 E/80O. Sesar tersebut diduga dikontrol oleh sesar mendatar opak yang memiliki arah tegasan utara-selatan. Hal ini juga diperkuat karena lokasi daerah penelitian berada pada jalur Sungai Opak.

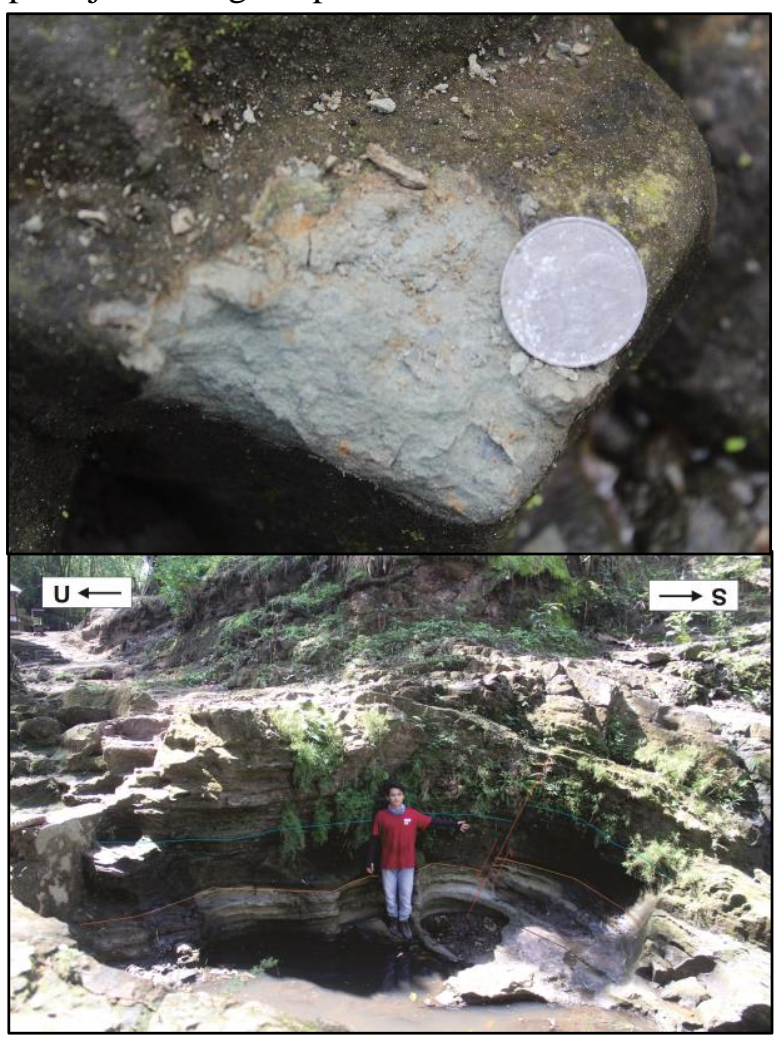

Gambar 2. a) Litologi tuff pada daerah penelitian, b). Struktur geologi berupa sesar turun pada daerah penelitian.

Karakteristik geologi yang ada di daerah penelitian berpotensi menjadi objek geowisata yang menarik. Singkapan batuan yang unik dapat menjadi daya tarik bagi wisatawan umum dan menjadi perhatian tersendiri bagi para ahli geologi. Daerah penelitian berpotensi menjadi objek wisata sekaligus objek penelitian terkait kondisi geologi yang berkembang di daerah tersebut. Belum adanya penelitian terkait kondisi geologi di daerah penelitian menjadi peluang untuk menarik pengunjung khususnya dari kalangan akademik maupun masyarakat umum yang tertarik akan objek-objek geologi. Batuan yang ada di lokasi penelitian juga masih belum diidentifikasi lebih lanjut karakteristik serta umur batuannya. Adanya fragmen batuan beku berupa bom pada singkapan batuan piroklastik daerah penelitian diduga merupakan hasil aktivitas vulkanik juga menarik untuk diteliti dari mana sumber aktivitas vulkanisnya.

Karakteristik geologi yang ada di daerah penelitian berpotensi menjadi objek geowisata yang menarik. Singkapan batuan yang unik dapat menjadi daya tarik bagi wisatawan umum dan

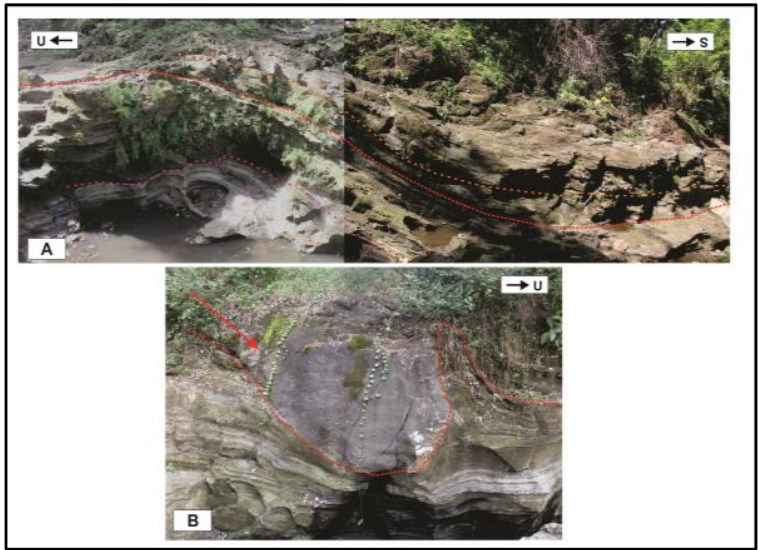

Gambar 5. a). Singkapan batuan pada daerah penelitian, b). Fragmen batuan beku dengan ukuran bom yang berada pada lapisan batuan piroklastik

menjadi perhatian tersendiri bagi para ahli geologi. Daerah penelitian berpotensi menjadi objek wisata sekaligus objek penelitian terkait kondisi geologi yang berkembang di daerah tersebut. Belum adanya penelitian terkait kondisi geologi di daerah penelitian menjadi peluang untuk menarik pengunjung khususnya dari kalangan akademik maupun masyarakat umum yang tertarik akan objek-objek geologi. Batuan yang ada di lokasi penelitian juga masih belum diidentifikasi lebih lanjut karakteristik serta umur batuannya. Adanya fragmen batuan beku berupa bom pada singkapan batuan piroklastik daerah penelitian diduga merupakan hasil aktivitas vulkanik juga menarik untuk diteliti dari mana sumber aktivitas vulkanisnya.

\section{Penilaian Geowisata}

Penilaian potensi geowisata yang dilakukan dengan metode deskriptif kuantitatif ini, nantinya akan menghasilkan penilaian layak atau tidak layak suatu daerah sebagai daerah geowisata yang berdasarkan pada pendekatan lima parameter yaitu nilai keilmuan dan intrinsik, edukasi, ekonomi, konservasi, dan nilai tambahan. Berdasarkan hasil penilaian kuantitatif yang dilakukan, didapatkan bahwa terdapat beberapa kekurangan dan kelebihan yang dimiliki daerah tersebut sebagai daerah geowisata. Pada parameter nilai edukasi masih belum sepenuhnya 
dimanfaatkan dengan maksimal karena lokasi ini masih jarang digunakan sebagai tempat penelitian untuk dipublikasikan di jurnal ilmiah dan belum dimanfaatkan sebagai wisata edukasi, sekarang ini baru digunakan untuk kepentingan mahasiwa sebagai tempat ekskursi. Sedangkan dari segi nilai ekonomi, aksesibilitas jalan sudah ada namun belum tersedia dengan baik, hanya dapat ditempuh dengan berjalan kaki atau kendaraan roda dua dengan jarak tempuh sekitar \pm 800 meter dari lokasi parkiran sedangkan untuk mobil aksesnya cukup sulit untuk masuk karena ukuran jalan yang relatif sempit.

Kemudian dari nilai tambahan ditinjau dari kondisi lapangannya, objek geowisata ini memiliki nilai ekologi yang mendukung dengan lokasi dikelilingi oleh bentuk lahan berupa tebing dengan berbagai kenampakan fenomena geologi yang unik serta nilai budaya yang sangat erat dengan kehidupan masyarakat, namun dari segi fasilitas masih ada yang kurang seperti pagar pengaman dan toilet. Selanjutnya dari nilai konservasi, situs objek geowisata memiliki resiko untuk rusak namun tidak terlalu besar karena materialnya yang cukup resisten, selain itu objek geowisata ini juga masih belum diresmikan oleh pihak yang berwenang sebagai daerah geowisata namun sudah ada usaha sebelumnya untuk mengajukan permohonan peresmian geowisata ini.

Namun, walaupun masih ada beberapa kekurangan di daerah geowisata ini. Berdasarkan dari hasil penilaian analisis kuantitatif berupa scoring dengan bantuan metode penilaian menurut Kubalikova (2013) situs geologi Bukit Watu Kapal masih layak untuk diajukan menjadi rancangan geowisata berdasarkan dari data yang ditunjukkan pada Tabel X. Hal ini didasarkan pada hasil analisis kuantitatif menurut Kubalikova (2013), yang angkanya harus melebihi persentase sebesar $50 \%$ untuk bisa dikatakan layak dilakukan pengembangan geowisata.
Tabel 1. Penilaian Potensi Geowisata

\begin{tabular}{|c|c|c|}
\hline A & Parameter & $\begin{array}{c}\text { Skor Nilai Keilmuan } \\
\text { dan Intrinsik }\end{array}$ \\
\hline 1 & Integritas & 0,5 \\
\hline 2 & Kelangkaan & 1 \\
\hline 3 & Diversitas & 0,5 \\
\hline 4 & Nilai Edukasi & 0 \\
\hline $\mathrm{B}$ & Parameter & Skor Nilai Edukasi \\
\hline 1 & $\begin{array}{c}\text { Kejelasan/ tingkat representatif } \\
\text { dari proses pada situs }\end{array}$ & 0,5 \\
\hline 2 & Percontohan dan kegunaan situs & 0,5 \\
\hline 3 & Kehadiran produk edukasi & 1 \\
\hline 4 & $\begin{array}{c}\text { Kegunaan aktual dari situs sebagai } \\
\text { geowisata }\end{array}$ & 0,5 \\
\hline $\mathrm{C}$ & Parameter & Skor Nilai Ekonomi \\
\hline 1 & Aksesibilitas & 0,5 \\
\hline 2 & Ketersediaan Infrastruktur Turis & 1 \\
\hline 3 & $\begin{array}{c}\text { Produk Lokal } \\
\end{array}$ & 0,5 \\
\hline $\mathrm{D}$ & Parameter & Skor Nilai Konservasi \\
\hline 1 & Bahaya dan resiko aktual dari situs & 0,5 \\
\hline 2 & $\begin{array}{c}\text { Potensi ancaman dan resiko } \\
\text { bahaya }\end{array}$ & 0,5 \\
\hline 3 & Status dari Situs & 0,5 \\
\hline 4 & Perlindungan Legislatif & 0,5 \\
\hline $\mathrm{E}$ & Parameter & Skor Nilai Tambahan \\
\hline 1 & Kesedian nilai budaya & 1 \\
\hline 2 & Nilai Ekologi & 1 \\
\hline 3 & Nilai Estetika & 0,5 \\
\hline 4 & Struktur Ruang & 0,25 \\
\hline 5 & Sudut pandang & 0,5 \\
\hline \multicolumn{2}{|r|}{ TOTAL SKOR } & 11,75 \\
\hline \multicolumn{2}{|r|}{ SKOR\% } & $63,5 \%$ \\
\hline
\end{tabular}

\section{Strategi Pengembangan Geowisata Daerah Penelitian}

Dalam pengmbangan geowisata daerah ini perlu dilakukan pengembangkan karakter terpadu dari produk-produk yang ada melalui pengembangan zona-zona tematis, bertumpu pada keunikan potensi alam geologi dan perpaduannya dengan budaya dan sejarah serta kondisi fisik daerah tersebut sebagai tema pengembangan sehingga memiliki pembeda khas dengan produk di daerah wisata atau area wisata lainnya. Pengalaman yang menyeluruh bagi wisatawan mengenai produk wisata (berupa objek atau layanan) dapat diciptakan melalui penetapan zona-zona tematis, yang berupa objek-objek dengan keunikan karakteristik yang menarik. Pengembangan objek dengan tema-tema khusus ini selain menciptakan alternatif pilihan bagi wisatawan, juga diharapkan mampu mendorong berkembangnya kawasan lain yang juga memiliki produk wisata yang spesifik serta membantu mengembangkan peluang-peluang usaha bagi masyarakat di sekitarnya. Selan itu juga perlu adanya upaya memperkuat kemitraan melalui 
kesadaran bersama terhadap makna lintas batas untuk menciptakan ruang-ruang pariwisata baru. Maka untuk mencapai hal tersebut, dibutuhkan kerja sama yang baik antara warga setempat dengan pemerintah Girimulyo serta organisasi yang bergerak dalam pengelolaan geowisata.

Usaha pengembangan lainnya adalah dengan dilakukannya pembinaan dan sosialisasi ke masyarakat, penguatan kapasitas sosial budaya di kawasan tersebut, pengembangan infrastruktur dan aksesibilitas jalan yang lebih baik, pembangunan sarana prasarana penunjang wisata, dan pengembangan tata ruang kawasan wisata dengan tetap memperhatikan kondisi dan keunikan geologi yang ada sebagai basis data kegiatan geowisata.

\section{Peta Geowisata dan Geotrack}

Peta Geotrack (Gambar.6) sekitar objek Watu Kapal mencangkup rancangan rute yang meliputi beberapa objek geosite terdekat. Perancangan rute geotrack didasarkan pada posisi geosite yang aksesbilitas lokasinya cukup dekat dan mudah untuk diakses. Rute perjalanan geotrack pada objek geosite yang meliputi objek Lava Bantal, candi Abang dan Tebing Breksi diperkirakan dapat ditempuh setengah hari, berikut rute geotrack yang dirancang peneliti, Watu Kapallava Bantal-Candi Abang-Tebing Breksi.

\section{KESIMPULAN DAN SARAN \\ Kesimpulan}

Berdasarkan hasil analisis dan skoring potensi pengembangan geowisata pada objek Watu Kapal, objek tersebut memiliki skor $63,5 \%$. Nilai tersebut menunjukan bahwa objek Watu Kapal sangat potensial untuk dikembangkan menjadi objek geowisata. Strategi pengembangan geowisata dengan pendekatan terhadap masyarakat, meningkatkan sarana prasarana dan penguatan sosial budaya diharapkan dapat dilakukan agar pengembangan objek menjadi geowisata dapat optimal.

\section{Saran}

Perlu adanya penelitian lebih lanjut mengenai kondisi geologi daerah penelitian seperti analisa umur batuan agar menunjang pemahaman tentang kondisi geologi daerah penelitian. Akses jalan dan penambahan fasilitas umum daerah penelitian perlu ditingkatkan agar memudahkan para wisatawan.

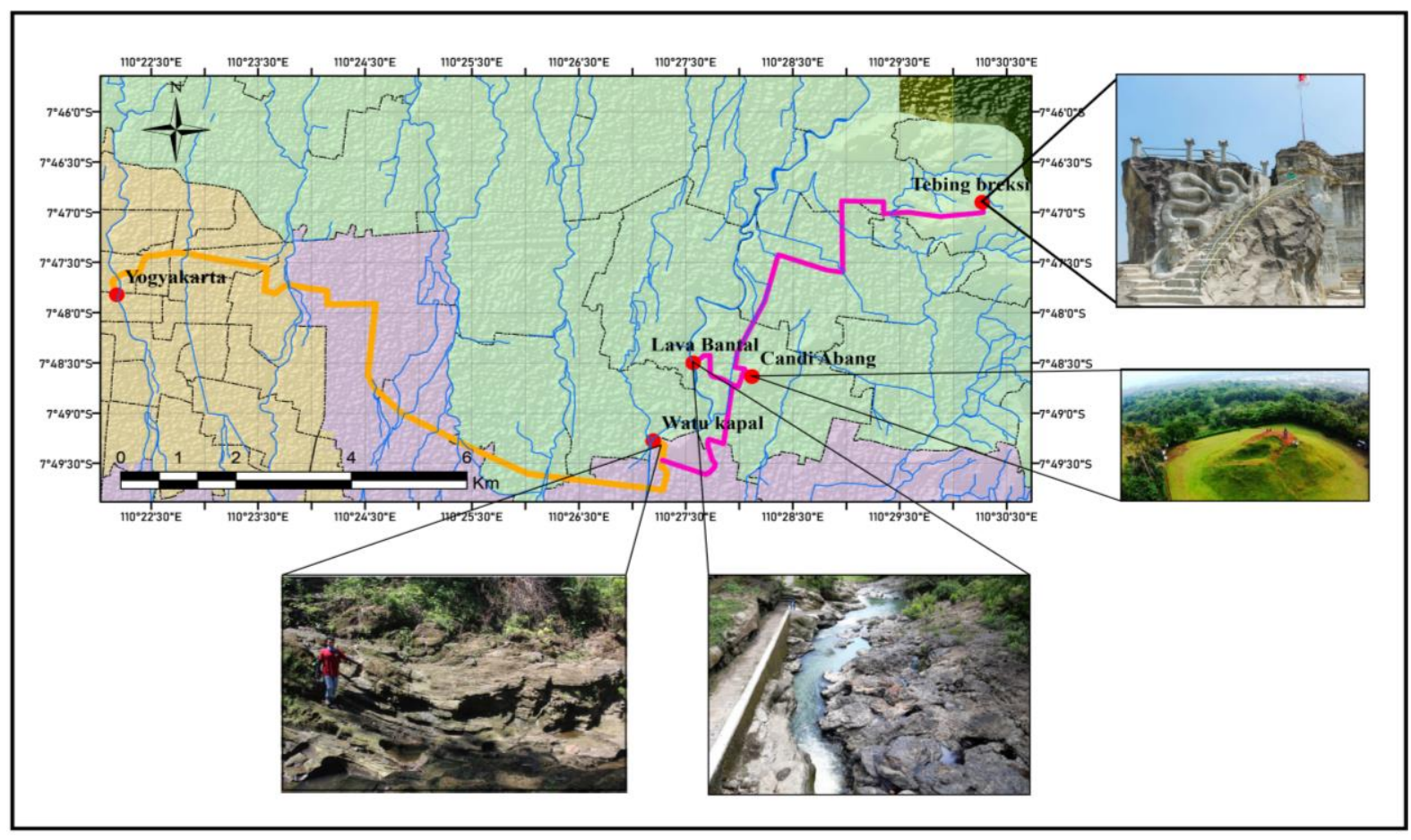

Gambar 3. Peta Geotrack Sekitar objek Watu Kapal 


\section{Referensi}

Ali, R. K., Qadaryati, N., \& ... (2021). Analisis Penilaian Situs Geologi Sebagai Peluang Pengembangan Geowisata di Kabupaten Bantul, Daerah Istimewa Yogyakarta. Jurnal Ilmiah Pariwisata, 26(1). http://jurnalpariwisata.stptrisakti.ac.id/index .php/JIP/article/download/1443/229

Bachri, S. (2014). Pengaruh Tektonik Regional Terhadap Pola Struktur dan Tektonik Pulau Jawa. Geologi Dan Sumberdaya Mineral, 15(4), 215-221.

Burkart, A. ., \& Medklik, S. (1988). Tourism : past present and future. English Languange Book Society (ELBS) Heineman Profesional.

Cahyani, A. A., Suharwanto, \& Astuti, F. A. (2020). Evaluasi Kesesuaian Lahan Kawasan Geowisata Tebing Breksi di Dusun Nglengkong, Desa Sambirejo, Kecamatan Prambanan, Kabupaten Sleman, D.I. Yogyakarta. Seminar Nasional Teknik Lingkungan Kebumian Ke, 33-45.

Dowling, R. K., \& Newsome, D. (2010). Global geotourism perspectives (WoodeatonOxford (ed.)). Goodfellow Publishers Limited.

James J, S. (1987). Pariwisata Indonesia: Sejarah Dan Prosesnya. Kanisius.

Newsome, D. (2006). Geotourism. Elsevier Ltd.

Permadi, R. W. A. P., Hadian, M. S. D. H., Yustikasari, Nugraha, A., \& Wulung, S. R. P. (2019). INVENTARISASI POTENSI GEOWISATA DI PROVINSI KALIMANTAN UTARA. Media Bina Ilmiah, 14(4), 2513-2520.

Putri, E. D. H. (2013). Pentingnya Menjaga Higiene Dan Sanitasi Di Lingkungan The Sahid Rich Hotel Yogyakarta. Khasanah Ilmu-Jurnal Pariwisata, 4(2).

Richard Sihite. (2000). Tourism Industry. PT Pradya Paramita.

Sabon, V. ., Perdana, M. ., Koropit, P. ., \& Pierre, W. (2018). Strategi peningkatan kinerja sektor pariwisata Indonesia pada Asean economic community. Esensi : Jurnal Bisnis Dan Manajemen, 8(2), 163-167.

Santosa, L. W., \& Adji, T. N. (2014). Karakteristik Akuifer Dan Potensi Airtanah Graben Bantul. Gadjah Mada University
Press.

Septian, Y., Srikandi, W. O. E., Manyoe, I. N., Taslim, I., Umar, P. E., Salama, T. H., \& Napu, S. S. S. (2019). Asesmen Nilai-Nilai Pariwisata Terhadap Fitur Geologi sebagai Pengembangan Geowisata Pesisir Selatan Gorontalo. Jurnal Azimut, 2(2), 146-154.

Silviany, A. . (2016). Upaya Provinsi Lampung Dalam Meningkatkan Wisatawan Mancanegara ke Teluk Kiluan Lampung. Universitas Pasudan.

Soebagyo, S. (2012). Strategi Pengembangan Pariwisata Di Indonesia. LIQUIDITY, 1(2), 153-158. https://doi.org/10.32546/LQ.V1I2.145

UNWTO. (2014). UNWTO Tourism Highlights. https://doi.org/https://www.eunwto.org/doi/pdf/10.18111/978928441622 6

Utomo, T., Yuwono, B., \& Amarrohman, F. (2017). Aplikasi Sistem Informasi Geografis Berbasis Web Dan Android Untuk Pemilihan Jalur Alternatif Menuju Tempat Pariwisata (Studi Kasus: Kota Wisata Cibubur Dan Jungleland, Kabupaten Bogor). Jurnal Geodesi Undip, 6(2), 1-11. 